\title{
Metabarcoding of Soil Fungal Communities from Perturbed Areas Reveal Drive Role of Environmental Factors in Microbial Diversity of Colombian Andosols
}

RAUL ALEXANDER ARANGUREN AROCA ( $\square$ raul.aranguren@udea.edu.co)

Universidad de Antioquia https://orcid.org/0000-0002-7090-7017

Samuele Voyron

University of Turin

Fabrizio Ungaro

National Research Council (CNR), Florence

Julio Cañón

Universidad de Antioquia

Erica Lumini

National Research Council (CNR), Turin

\section{Research Article}

Keywords: Soil fungal metabarcoding, Nested PCR approach, Response Ratio, Alpha diversity, Relevant taxa

Posted Date: December 6th, 2021

DOI: https://doi.org/10.21203/rs.3.rs-1128776/v1

License: @ (i) This work is licensed under a Creative Commons Attribution 4.0 International License. Read Full License 


\section{Abstract}

Changes in soil fungal community caused by land use have not been sufficiently studied in South-American Andosols, considered globally as important food production areas. This study analyzed 26 soil samples of Andosols collected from locations devoted to conservation, agriculture and mining activities in the southeastern region of Antioquia, Colombia, to establish differences between fungal communities as indicators of the degree of soil perturbation. The study developed a novel heminested PCR with primers SSUmCf Mix, ITS4 and fITS7 to assess Arbuscular Mycorrhizal Fungi detection in a Illumina MiSeq metabarcoding on nuclear ribosomal ITS2 region. A non-metric multidimensional scaling allowed exploring driver factors of fungal community changes, while fitted Dirichlet-multinomial models and PERMANOVA tests allowed identifying the correlations between alpha diversity indexes and community dissimilarities, as well as the significance of land use effects on fungal community composition. Furthermore, response ratios were determined to assess effect size by land use over relevant taxa. Results suggest a good coverage of fungal diversity with a detection of 10,529 high-quality ITS2 sequences belonged to phylum Glomeromycota. The analysis shows strong correlations of Shannon and Fisher indexes with dissimilarities on fungal communities among land uses $(r=0.94)$, related to variations in temperature, air humidity and organic matter contents that lead to significant responses in abundances of relevant orders (such as Wallemiales and Trichosporonales). The study highlights the rich fungal biodiversity of the tropical Andosols, their specific sensitivities to environmental perturbation factors, and the useful range of a metabarcoding approach to characterize soil fungal communities.

\section{Introduction}

Changes in the structure and composition of soil fungal communities are important indicators of soil quality as soil functions, related to nutrient cycling, ecosystem provisioning, and climate regulation, can decrease due to loss of fungal diversity (Brinkmann et al. 2019; Li et al. 2019). Despite having information about the effect of different land uses on tropical soil fungal communities, the distribution of fungal taxa, functional groups and biogeographic patterns are still analyzed poorly and discontinuously at local-scale in Colombian soils (Landinez-Torres et al. 2019).

Tropical Andosols represent more than $50 \%$ of the global Andosol land area and are an important unit of global agricultural productivity due to their coarse texture, high porosity, low cohesion and tendency to accumulate more organic matter (Anda and Dahlgren 2020; Kassaye et al. 2020; Pushkareva et al. 2021). Specifically, Andosols in central Colombia are considered complex microbial habitats and important water reservoirs, in view of their high spatial variation in phreatic zones, thickness of organic horizons and effective cation exchange capacity (Casamitjana et al. 2020). However, there is a lack of information to understand how human actions can affect the richness of fungal communities and their compositions in these Andosols. The analysis of soil fungal communities at local scale is the base of studies on their ecological behavior because local abiotic and biotic conditions, specific to the bioclimatic region or habitat, affect soil fungal community composition (Alzarhani et al. 2019). Furthermore, assessing the effect of specific land uses on individual soil microbial taxa is key to propose management practices of the soil microbial diversity to maintain or increase soil quality (Victorino et al. 2021).

Identification of fungal taxa associated with soils is necessary for understanding these complex communities (Pauvert et al. 2019). Techniques, such as metabarcoding based on sequences of the internal transcribed spacer (ITS) region, have been recognized as the universal barcode for a correct taxonomic identification of fungal community members with potential to detect rare species in samples of different nature, including poor sequenced taxa (Badotti et al. 2017; Forin et al. 2018). Characterization of fungal communities using metabarcoding of ITS region sequences have expanded the capability to identify land use effects that shape these communities across space and time, associated to factors such as leaf litter, soil nutrients, $\mathrm{pH}$ and organic matter content (Rosenfeld et al. 2018; Sommermann et al. 2018; Turley et al. 2020). Tropical soils are important units to study fungal ecological preferences and their driving factors, considering that diversity of fungal groups can peak in tropical ecosystems (Tedersoo et al. 2014). Previous studies tested laboratory protocols and obtained good ITS amplicon pools from soils typical of tropical ecosystems such as rainforest, dry forest, littorals, coasts and Andeans forest (Barnes et al. 2016; Ritter et al. 2020; Urbina et al. 2016). The biodiversity assessments of these studies showed shifts of fungal dominant taxa, increases of facultative fungal abundances in deforested areas (Shi et al. 2019), declines of fungal richness and diversity indexes by increments of phosphoric fertilization rates (Liu et al. 2018), and positive correlations between pathogenic fungal distribution and soil fertility factors (Castaño et al. 2019). 
Despite the extensive use of ITS metabarcoding to characterize fungal communities, particular settings on the primers used during PCR amplifications are necessary to avoid universal primer bias and increase the identification of specific fungal groups. For instance, ITS universal barcoding primers that are commonly used to characterize the whole fungal community of soil are considered suboptimal for Arbuscular Mycorrhizal Fungi (AMF) characterization (Berruti et al. 2017). However, the use of ITS specific primers can improve the identification of AMF (Waud et al. 2014). Although SSU and ITS2 primers such as SSUmCf, fITS9 and fITS7 provide a good survey of AMF community structure and diversity patterns, molecular approaches developed for estimating soil AMF diversity are still weak at characterizing species and have discrepancies in the taxonomic composition (Krüger et al. 2009; Berruti et al. 2017). Since the combinations of fungal primers should be used to enhance identification of underrepresented groups by universal barcodes such as Glomeromycetes (George et al. 2019), evaluations of the impact of primer selection in AMF community analysis, in different environment samples, may be needed to draw more general conclusions regarding the primer selection and PCR protocol most suitable for metabarcoding studies on AMF communities (Suzuki et al. 2020). In addition, characterization of fungal communities in particular soil types by Illumina MiSeq metabarcoding and new amplification approaches may boost the molecular methods to identify AMF taxa as a result of new representative sequences obtained from AMF present in specific host plants (Barbosa et al. 2021).

This study characterizes fungal communities in tropical Andosols, developing a novel heminested PCR approach with primers SSUmCf Mix, ITS4 and fITS7 to assess AMF detection. We tested how features and relevant taxa of soil fungal communities vary among three land uses with different degrees of perturbation in the southeastern region of Antioquia, Colombia. Illumina MiSeq soil DNA metabarcoding on nuclear ribosomal ITS2 region was used to describe total fungal diversity and in particular those of AMF taxa of sites: (1) relatively undisturbed within conservation areas; (2) subject to pressure by agriculture activities; and (3) subject to considerable pressure by mining activities related to clay extraction.

The features of fungal communities compared in this study allows establishing the effect size of land use on soil biodiversity, based on the hypothesis that changes in features of fungal communities reflect the effect of different degrees of perturbation. In the frame of an increasing demand to understand the factors driving fertility and microbial diversity of soils, the results revealed how environmental factors and soil properties change among different land uses and alter the key fungal components.

\section{Materials And Methods}

\section{Study site and characterization of land uses}

The field research took place during a rainy season in three municipalities (La Ceja, El Retiro and Rionegro), in the southeastern region of Antioquia, Colombia (Fig.1). The municipalities are located in the central Andes mountain range at altitudes between 2300 and 2700 m.a.s.I.. Pre-montane humid forest and mosaics of pasture-crops are typical ecosystems in the region, which exhibits a unimodal temperature cycle with an average temperature of $21^{\circ} \mathrm{C}$ and an annual bimodal precipitation cycle with an average monthly precipitation of $387 \mathrm{~mm}$. Within each municipality, the study collected samples of Andosols topsoil in each of the three targeted land uses: unperturbed areas for conservation (UnPA), areas managed for agricultural activities (AgA), and areas of mining extraction (MeA).

A point-transect sampling was carried out along 100-m transects delineated from the centroid of the polygon that encompassed each land use. Three equidistant points (at $50 \mathrm{~m}$ ) were selected along each transects. Five subsamples (soil cores at $20 \mathrm{~cm}$ depth) were taken within a $2 \mathrm{~m}$ radius of each point to make a composite soil sample, using a soil auger with a diameter of $5 \mathrm{~cm}$. $27 \mathrm{composite}$ soil samples were collected and stored in plastic bags at $4^{\circ} \mathrm{C}$ for further analyses. Environmental variables (soil temperature, air relative humidity, dew point temperature and barometric pressure) and soil variables $(\mathrm{pH}$, total dissolved solids and electrical conductivity) were measured with a Kestrel 5500 Weather Meter and a Lamotte TRACER 1766, respectively. Organic carbon was quantified after by wet digestion method (Benbi 2018), and soil moisture following thermo-gravimetric technique (Susha Lekshmi et al. 2014).

\section{DNA extraction and PCR amplification}

DNA was extracted, from $0.25 \mathrm{~g}$ of soil, previously sieved through $2 \mathrm{~mm}$ pore size sieve, with DNeasy PowerSoil kit (Qiagen, Hilden, Germany), following the manufacturer's protocol. To improve the number of AMF sequences detected, the ITS2 nuclear ribosomal region was amplified using Invitrogen Platinum HotStart PCR Master Mix (Thermo Fisher Scientific) by means of a heminested PCR 
approach. In the first PCR, the entire ITS region (ITS1-5.8S-ITS2) was amplified with the fungal primers SSUmCf Mix (Krüger et al. 2009) and ITS4 (White et al. 1990). The cycling conditions were an initial step at $95^{\circ} \mathrm{C}$ for $5 \mathrm{~min}, 35 \mathrm{cycles}$ at $95^{\circ} \mathrm{C}$ for $30 \mathrm{~s}, 54^{\circ} \mathrm{C}$ for $45 \mathrm{~s}, 72^{\circ} \mathrm{C}$ for $1 \mathrm{~min}$, and a final extension step of $72^{\circ} \mathrm{C}$ for $7 \mathrm{~min}$.

The obtained PCR products (c.ca $750 \mathrm{bp}$ ) were checked on 1.2\% agarose gel, diluted at 1:20-1:100 and used as template in the heminested PCR targeting the ITS2 region, with primers fITS7 (Ihrmark et al. 2012), and ITS4 endowed of the following Illumina overhang adapter sequences: forward overhang: 5'-TCGTCGGCAGCGTCAGATGTGTATAAGAGACAG- and reverse overhang: $5^{\prime}$ GTCTCGTGGGCTCGGAGATGTGTATAAGAGACAG-. The heminested PCR cycling conditions were as follows: an initial step at $95^{\circ} \mathrm{C}$ for $15 \mathrm{~min}, 27$ cycles at $95^{\circ} \mathrm{C}$ for $30 \mathrm{~s}, 57^{\circ} \mathrm{C}$ for $30 \mathrm{~s}, 72^{\circ} \mathrm{C}$ for $30 \mathrm{~s}$, and a final extension step of $72^{\circ} \mathrm{C}$ for $7 \mathrm{~min}$. PCR products were purified by means of Wizard SV Gel and PCR CleanUp System (Promega), quantified using Qubit 2.0 (Thermo Fisher Scientific, Waltham, MA, USA) and sent to IGA Technology Services S.R.L (Udine, Italy) for Illumina MiSeq platform sequencing ( $2 \times 300 \mathrm{bp}$ ).

\section{Bioinformatics and statistical analysis}

Raw Sequence data were processed using the Quantitative Insights Into Microbial Ecology 2 software package (QIIME2 version 2020.6.0) (Bolyen et al. 2019). To avoid poor quality sequences, reads were truncated (>280 bp for forward,> 265 bp for reverse reads). The classifier adopted to generate the taxonomic assignment was UNITE community 2020: UNITE QIIME release for Fungi version 20.02.2020. Sequences with $\geq 97$ similarity were assigned to the same Operational Taxonomic Unit (OTU). The fungal sequencing data were uploaded to the NCBI SRA database under accession number PRJNA779046.

The generated dataset and metadata were used to create a phyloseq object with the R package "phyloseq" version 1.38 (McMurdie and Holmes 2013). Then, rarefaction curves were plotted to observe the level of OTUs saturation richness reached in every specific activity assessed. The total number of reads per sample was rarefied to the lowest sequencing depth (Cox et al. 2019; Lauber et al. 2013) to allow statistical comparisons. The OTU table was rarefied at 1,417 sequences per sample by means of the 'rarefy_even_depth' function (Victorino et al. 2021).

To identify taxa with a relevant role in the fungal communities, the number of samples in which each species occurs (expressed as average prevalence, aP) was estimated and the most frequent species in every land use were identified. A permutation-based test of Multivariate Homogeneity of group dispersions (PERMUTEST) followed by Permutational Multivariate Analysis of Variance (PERMANOVA) (each one with 999 permutations) was performed to assess the variation of environmental attributes, soil properties, fungal community composition (at different rank level) and alpha diversity indexes among land uses and municipalities. With PERMUTEST the assumption of equal data dispersion among samples was assessed.

Afterwards, abundances of taxa significantly different among land uses were highlighted by generating a heat-map diagram based on Bray-Curtis similarity coefficients (Pang et al. 2019). These coefficients were used to group soil samples with a hierarchical clustering analysis. Then, adopting a non-metric multidimensional scaling (NMDS) a gradient analysis was developed to highlight the driving role of environmental factors and soil properties on the ordination of those taxa abundances and alpha diversity indexes (Chao1, ACE, Shannon $\left(H^{\prime}\right)$, Simpson (D'), Inverse Simpson (1/D') and Fisher $\left.\left(S^{\prime}\right)\right)$.

The NMDS, PERMUTESTs and PERMANOVAs were performed with R package "vegan" version 2.5 (Oksanen et al. 2020), adopting the Bray-Curtis dissimilarity coefficients as partitioning of variation (Ontivero et al. 2020). Through the function 'envfit' the environmental vectors were fitted onto the NMDS ordination plot to identify the environmental variables and soil properties that drive changes in the fungi community. Subsets of alpha diversity index with a maximum rank correlation with communities' dissimilarities were identified through fitted Dirichlet-multinomial models (Torondel et al. 2016).

Finally, using the Response Ratio Index (RRi) (Gao et al. 2021), we calculated the effect size produced by land uses on abundance of prevalent species, dominant taxa related to fungal communities cluster and diversity indexes. The results observed in UnPA were considered as control groups. The RRis were estimated with the R package SingleCaseES version 0.4.4 (Swan and Pustejovsky 2018). An unpaired two-sample Wilcoxon test was used to evaluate whether the Absolute Response Ratio (ARR) means were different between comparisons UnPA vs AgA and UnPA vs MeA.

\section{Results}

\section{Sequencing and soil fungal community composition}

Page $4 / 22$ 
The PCR heminested approach produced a set of 3,524,761 raw sequences, with 353,312 high-quality ITS2 sequences, averaging 11,330 sequences per sample, retained after the denoising process. Twenty-six samples were used for downstream analyzes. Despite the higher number of valid sequences, land use MeA presented a lower number of OTUs. On the contrary, UnPA and AgA showed the highest number of OTUs (Table.1). Rarefaction curves suggest that a plateau was reached (Fig.2), indicating that the sampled environments have a good representation of the fungal community, with the identification of 489 OTUs, 9 phyla, 29 classes, 53 orders, 117 families, 158 genera and 174 species.

Among the 489 OTUs, 213 belonged to the Basidiomycota, 167 to the Ascomycota, 25 to the Mucoromycota, 17 to the Mortierellomycota, 16 to the Glomeromycota, and 41 to unassigned phyla. The heminested PCR approach allows identifying 10,529 (2.98\%), high-quality ITS2 sequences of phylum Glomeromycota (4 orders and 6 families). Claroideoglomus (Family Claroideoglomeraceae) was the unique genus assigned. UnPA (5,302 sequences) has the highest number of Glomeromycota sequences, followed by MeA (2,709 sequences) and $\mathrm{AgA}$ (2,518 sequences) land uses. Some families such as Ambisporaceae and Acaulosporaceae were only present in the mining sites of La Ceja (LC-QC) (Table.2).

UnPA (40.95\%) and MeA (56.29\%) land uses have high relative abundance of Basidiomycota OTUs. However, the relative abundance of Ascomycota OTUs was the highest in AgA (32.40\%) and displayed an increase in UnPA (37.20\%). In addition, UnPA and AgA land uses showed an increase of Ascomycota, Mucoromycota, Glomeromycota and Mortierellomycota OTUs abundance, in comparison to MeA. The more abundant orders in the study zone were Hypocreales (16.26\%), Agaricales $(10.02 \%)$ and Malasseziales (8.88\%). Hypocreales was the most abundant order in UnPA (3236 reads) and AgA (2466 reads). Malasseziales was the order with higher abundance in MeA (2611 reads). Nevertheless, this order was scarcely observed in UnPA (3 reads) (Fig.3).

UnPA contained 116 species, AgA 68 species and MeA 47 species. The most frequent species in every land use have similar prevalence (Table.3), with the frequent species in MeA land use being the less prevalent. Saitozyma $s p$. was the most frequent species in UnPA, whereas Trichoderma asperellum and Agrocybe pediades were the most frequent in AgA and MeA land uses. Malassezia $s p$. was prevalent and highly abundant in both perturbed land uses.

\section{Soil fungal communities among land uses}

The municipalities did not show significant differences at phylum and order rank. However, fungal taxa varied more strongly with land uses at the rank of order followed by the genera. Contrasting fungal genera abundances among land uses were only significant between UnPA-MeA $\left(R^{2}=0.139, p=0.002\right)$ and AgA-MeA $\left(R^{2}=0.121, p=0.01\right)$, with significant differences at the order rank in abundances between UnPA-AgA $\left(R^{2}=0.106, p=0.023\right)$, UnPA-MeA $\left(R^{2}=0.189, p=0.001\right)$ and AgA-MeA $\left(R^{2}=0.122, p=0.018\right)$. In addition, the abundance of dominant fungal orders displayed a meaningful distribution among land uses. For instance, samples from UnPA showed a high abundance of orders Hypocreales and Agaricales. Higher abundance of order Malasseziales was representative of MeA soil grouped samples. The cluster analysis of order composition shows two main groups of samples. The first group matches most of the samples retrieved on MeA while the second group involves samples from UnPA and AgA land uses (Fig.4).

Land uses show variations in the Alpha diversity indexes, with significant differences observed between UnPA-AgA (R2=0.412, $p=0.006)$, UnPA-MeA ( $2=0.709, p=0.001)$ and AgA-MeA $(R 2=0.514, p=0.002)$. However, the differences in abundances of taxa and alpha diversity indexes were not significant between municipalities. Higher alpha diversity values occurred in the UnPA land use, highlighting values observed in LC-MpMWF samples. Inversely, lower values occurred in MeA, especially in ER-QC and LC-QC (Fig.5). The alpha-diversity indexes showed consistent patterns among land uses (UnPA > AgA > MeA).

\section{Fungal diversity responses to variations in soil properties and environmental factors}

The studied Andosols have an acidic to weakly acidic pH range (from 5.3 to 5.7), with some parameters such as organic carbon content and soil moisture decreasing with the degree of perturbation. On the contrary, other parameters such as electrical conductivity and total dissolved solids increase with the degree of perturbation. Similarly, environmental parameters like relative air humidity and barometric pressure decrease in perturbed areas and other parameters such as soil temperature increase in those areas (Table.4). In AgA samples, $\mathrm{pH}$ and soil temperature decreased. In general, soil properties and environmental variables show a significant variation among land uses $\left(R^{2}=0.3182, p=0.0002\right)$.

The NMDS dissimilarity distance matrix with Bray-Curtis, performed to assess variability in community composition among land uses and specific activities, revealed that fungal communities of MeA were distinct from the other two land uses, observing a closer

Page 5/22 
similarity between fungal communities from UnPA and AgA. The communities order composition positively correlates with relative air humidity and organic matter and negatively correlates with soil temperature and dew point temperature (Fig.6a). Three groups in the sample ordination, based on alpha diversity indexes, showed positive correlation with organic matter and negative correlation with $\mathrm{pH}$ (Fig.6b). The subset of indexes with the maximum rank correlation with samples dissimilarities was shaped by Shannon and Fisher index $(r=0.94)$. Each vector had a substantial effect on the sample gradient ordination $(p=0.001)$. However, every subset of indexes strongly correlates $(r=>0.70)$ with dissimilarities in the communities.

\section{Effect size measure of land use}

UnPA and MeA showed a significantly high contrast in the ARR or effect size of differences observed in fungal community features and parameters assessed (Table.5). In general, land use intensity negatively affected abundances of prevalent fungal species, dominant order, alpha diversity index and environmental variables. The factors significantly affected by MeA and AgA land uses were the abundances of taxa belonging to order Wallemiales, Trichosporonales and organic matter. Despite this, the RRi soil moisture was significant in contrasting UnPA and MeA land uses, but not significant in contrasting UnPA and AgA land uses (Fig.7).

\section{Discussion}

\section{Soil fungal community in Colombian Andosols}

The average of high-quality ITS2 sequences and the percentage of sequences retention obtained with the heminested PCR approach were comparable with previous sequencing efforts of fungal communities in similar tropical soils. For example, ITS2-ITS4 barcode approach to fungal characterizations of soils from subtropical wet forest got an average of 11,293 high-quality ITS sequences, $44.97 \%$ of sequences retained (Urbina et al. 2016). The high number of species found in Andean soils contrasts with the low number detected in similar soils and land uses from lower altitudes. In Andean agricultural soils of Boyacá, Colombia (located at 2800 m.a.s.I), 143 species were identified among 6 phylum by a deep sequencing of the ITS1 barcode (Landinez-Torres et al. 2019), whereas just 30 fungal species were identified by a ITS1-ITS2 barcode approach in Andosols from Mexican pine forest, corn fields and rosebush (located at 1300 to 1700 m.a.s.I) (Munguía-Pérez et al. 2011). Studies on fungal communities along altitudinal gradients have suggested that altitude and related environmental factors such as air humidity and soil temperature affect fungal community structure (Geml et al. 2014). However, we include the influence of soil properties, because differences in specific fungal taxa assembly often correlate with soil characteristics such as nitrogen content, water retention, $\mathrm{pH}$, and cation exchange capacity (Essene et al. 2017).

In this study, Glomeromycota was a phylum rarely observed. However, among the found small set of high-quality ITS2 sequences of this phylum, 14 taxa were discriminated. Previous fungal community characterizations in comparable environments have reported less AMF diversity values. For example, Landinez-Torres et al. (2019) tested in Colombian Inceptisols (located at 2,900 m.a.s.l) an ITS1 region amplification by primers BITS and B58S3 identifying for Glomeromycota phylum (among 8 taxa) only 2 orders, 2 families (Glomeraceae and Acaulosporaceae) and 2 species (Glomus mosseae and Entrophospora infrequens). The low number of species of AMF discriminated through the heminested PCR approach tested can be ascribable to limits of universal primers targeting the ITS region. Nevertheless, nested PCR approaches could be preferred using mycorrhizal specific primer for detection of AMF (Kumar 2018). For instance, a similar PCR heminested approach with primers fITS9-ITS4 to amplify ITS2 region was useful to improved discrimination of AMF genus in a general fungal community characterization (Victorino et al. 2021).

In the Colombian Andosols analyzed in this study, sequences of phylum Basidiomycota were frequently present, especially in mining areas. This result corroborates the findings of other authors, in which the majority of fungi in tropical Andosols collected from warmer forest-crops mosaics and perturbed ecosystems (as forest fragmented and areas where vegetation was totally removed), belonged to phylum Basidiomycota (Gavito et al. 2019; Marín et al. 2017). For the mining areas sampled, Malassezia sp. was the most abundant, without being the most prevalent species. This result could have implications on the congregation of MeA samples based on order abundances, characterized by a large abundance of Malaseziales sequences. The results suggest that the relevant presence of these taxa in perturbed areas relate to low organic matter contents, since acidification caused by the loss of organic matter might be a factor that favours the abundance of Malassezia genus (Zhou et al. 2020).

Furthermore, clustered samples from UnPA and AgA showed a high abundance of order dominant Hypocreales (phylum Ascomycota) and Agaricales (phylum Basidiomycota). In UnPA land use, factors such as higher air humidity, lower soil temperature, wild vegetation 
and the absence of pesticide applications can promote the abundance of the prevalent species belonging to Hypocreales order. For example, fungi belonging to Metarhizium genus are endophytic entomopathogenic whose preferences for habitat selection respond to temperate environments, vegetative cover, high humidity and associations with insect hosts (Guerrero-Guerra et al. 2013; McGuire and Northfield, 2020). Likewise, Fusarium solani abundances are robustly associated with factors such as high soil moisture and presence of entomopathogenic nematodes (Wu et al. 2019). The higher prevalence of Saitozyma sp. (order Tremellales) in UnPA can relate to the litter observed in the sampled environments (Pre-montane wet forest and Forestry crops of Pinus sp.) as the Saitozyma genus is an important yeast able to incorporate carbon into soils. The high abundance of Saitozyma is typical of soils with abundant litter (Mašínová et al. 2017). In AgA land use, the high abundance of Ascomycota sequences was confirmed by the prevalence of Trichoderma asperellum, a fungal species with distribution patterns associated with typical Andean crops and coniferous forest (Argüelles-Moyao and Garibay-Orijel 2018; Mohammad Golam Dastogeer et al. 2020; Hoyos-Carvajal et al. 2009).

\section{Degree of soil perturbation and effect size on soil fungal community}

From the comparison of fungal communities among municipalities, the lack of significant differences between communities composition highlight the spatial homogeneity at local scale of the fungal biome in the study area. The distribution of the fungal community could therefore relate to abundance of organic resources suitable for exploitation by them and current environmental conditions (Orgiazzi et al. 2013). The results reported in this study indicate significant and analogous effects of land use on soil fungal community composition.

The NMDS ordinations showed a consistent gradient separation of soil fungal samples based on land uses. Samples from unperturbed areas clustered near samples from agricultural areas and substantially far from samples of highly perturbed mining areas. Furthermore, soils from native unperturbed areas that were $20 \mathrm{~km}$ and $25 \mathrm{~km}$ apart (locations RN-pMWF to ER-UpSH; LCMpMWF) were more similar in fungal order composition than those from agricultural and mining extraction areas within the same municipality. The PERMANOVA $R^{2}$ values suggest that the land use factor can explain approximately $10 \%$ and $18 \%$ of the variation observed in fungal order composition (contrasting UnPA vs AgA and UnPA vs MeA respectively). On the other side, land uses explain important variations on alpha diversity index in the same contrasting uses (41\% variation in UnPA vs AgA and $70 \%$ variation in UnPA vs MeA).

The observations illustrate the correspondence between dissimilarities of fungal composition in samples with the effect size (RRi) on specific taxa abundances, environmental parameters and soil organic matter. The land use gradient displays correlations with relative air humidity and organic matter content and negative correlations with soil temperature and dew point temperature. Much of these land use effects may be due to clearances of vegetation and partial removals of topsoil horizons from the sampled agricultural areas and mining sites, causing a reduction of soil moisture and nutrients (from litter), as well as a significant increment in temperature (Simmons et al. 2008; Zhao et al. 2019). The corresponding soil temperature increments and humidity loss in every perturbed area correspond to an enlargement of the effect size observed in the abundances of order Wallemiales (RRi=8.16) and Trichosporonales (RRi=-7.33). For instance, Jančič et al. (2016) documented temperature increments and humidity loss as a growth-promoting factor to Wallemia muriae populations. Conversely, populations of Apiotrichum scarabaeorum, a representative taxa of temperate wet forest dominated by deciduous trees, decrease in soils with low organic matter contents and moisture (Mašínová et al. 2017).

Soil fungal alpha diversity was the best ordination model of samples gradient as a function of the degree of soil perturbation. The patterns obtained for every alpha diversity index among land uses indicated that fungal richness was higher in unperturbed areas and decreased conforming perturbation degree increased in each land use. This qualitative divergence between perturbation degree and fungal alpha diversity resulted in a significant association of dissimilarities in alpha diversity communities with the Shannon and Fisher index. Land use effect size over these alpha diversity indexes suggest that the primary fungal community features affected by land use relate to the ratio of the number of taxa and the abundance of those taxa (Fisher index ARR average $=0.88$ ) followed by the taxa richness (Shannon index ARR average= 0.56 ). In the validation of those observations, the sequence abundances of the most relevant taxa (such as prevalent species and dominant order) were negatively affected by land use change, despite high average ITS valid sequences in agricultural (12,486 sequences) and mining areas (15,029 sequences). Furthermore, species richness downturned from 116 species identified in unperturbed areas, to 68 in agricultural areas and 47 species in mining areas.

The fungal community homogeneity at local scale observed in this study can represent a stable microbial consortium whose variability depends mainly on environmental and physic-chemical gradients in soil. The results support the hypothesis that relevant fungal taxa can be a useful tool for gaining insights into the structure of the soil microbiome, since relevant taxa in perturbed areas 
facilitate the identification of responses of soil microbiomes to environmental factors (Xiao et al. 2021). Likewise, the stronger response of alpha diversity indexes to the degree of perturbation found in this research is an important indicator of the fungal community perturbation patterns, rather than the abundance pattern of soil fungi taxa (Wang et al. 2015).

\section{Conclusions}

The species composition and structure of fungal communities in the assessed Colombian Andosols reveal the richness of soil fungal species compared to similar soil types. Our results provide a validation of the heminested approach using the primers set SSUmCf Mix-ITS4 and fITS7-ITS4 and Illumina MiSeq platform sequencing, to investigate fungal communities in Andosols. This approach has proven to be at least as accurate and comparable to other PCR based methods used for soil fungal community characterizations. In particular, the discrimination observed at rank of order and families indicate that the amplification of ITS2 region could be helpful to unravelling Glomeromycota diversity with major resolution.

The relevant taxa such as prevalent species and dominant order Hypocreales, Agaricales, Wallemiales and Trichosporonales were good indicators of the land use effect over soil fungal community. Factors such as air humidity, soil temperature and soil organic matter contents were more important as drivers than other edaphic factors that determined order composition dissimilarities among land uses or perturbation degree patterns. The Response Ratio in abundances of prevalent species belonging to dominant orders allowed the identification of deeper changes on soil fungal communities led by driving factors. However, effect size trends observed in alpha diversity indexes are better at discriminating changes in soil fungal communities according to the degree of soil perturbation under contrasting land uses.

\section{Declarations}

Funding: The research leading to these results received partial funding from program national doctorates auspicated by Colombian Ministry of Science, Technology and Innovation "COLCIENCIAS" under Grant Agreement number 727 of 2015. Likewise, partial financial support was received from the Research Group in Environmental Management and Modeling "GAIA" (Medellín, Colombia), the Institute for Sustainable Plant Protection (IPSP-CNR, Turin) and the Institute of BioEconomy (IBE-CNR, Florence) of the National Research Council of Italy.

Data availability: The datasets generated and analyzed during the current study are available from the corresponding author upon publication.

Ethics approval: Not applicable.

Consent to participate: Not applicable.

Consent for publication: The authors give their consent for publication.

Research involving human participants and/or animals: No human participants or animals were involved in this research.

Informed consent: This research did not involve human participants.

Conflict of interest: The authors declare no competing interests.

Code availability: Not applicable.

Acknowledgments. The authors wish to thank the Secretariat of Environment and Agricultural Development of Envigado, La Ceja and El Retiro who provided access to their fields and protected areas. Professor María Teresa Flórez at Universidad de Antioquia provided field and technical guidance on soils retrieval, structure and composition analysis. We are grateful to Marcela Mercado, Andres Montes, Nohora Gutierrez, Ivan Gonzalez and Jhefry Valencia for their assistance in the field and their excellent suggestions on earlier versions of the manuscript.

\section{References}

1. Alzarhani AK, Clark DR, Underwood GJC, et al (2019) Are drivers of root-associated fungal community structure context specific? ISME J 13:1330-1344. https://doi.org/10.1038/s41396-019-0350-y

Page $8 / 22$ 
2. Anda M, Dahlgren RA (2020) Mineralogical and surface charge characteristics of Andosols experiencing long-term, land-use change in West Java, Indonesia. Soil Sci Plant Nutr 66:702-713. https://doi.org/10.1080/00380768.2020.1820758

3. Argüelles-Moyao A, Garibay-Orijel R (2018) Ectomycorrhizal fungal communities in high mountain conifer forests in central Mexico and their potential use in the assisted migration of Abies religiosa. Mycorrhiza 28:509-521. https://doi.org/10.1007/s00572-018-0841-0

4. Badotti F, De Oliveira FS, Garcia CF, et al (2017) Effectiveness of ITS and sub-regions as DNA barcode markers for the identification of Basidiomycota (Fungi). BMC Microbiol 17:1-12. https://doi.org/10.1186/s12866-017-0958-X

5. Barnes CJ, Maldonado C, Frøslev TG, et al (2016) Unexpectedly high beta-diversity of root-associated fungal communities in the Bolivian Andes. Front Microbiol 7:1-13. https://doi.org/10.3389/fmicb.2016.01377

6. Benbi DK (2018) Evaluation of a rapid microwave digestion method for determination of total organic carbon in soil. Commun Soil Sci Plant Anal 49:2103-2112. https://doi.org/10.1080/00103624.2018.1495732

7. Berruti A, Desirò A, Visentin S, et al (2017) ITS fungal barcoding primers versus 18 S AMF-specific primers reveal similar AMFbased diversity patterns in roots and soils of three mountain vineyards. Environ Microbiol Rep 9:658-667. https://doi.org/https://doi.org/10.1111/1758-2229.12574

8. Bolyen E, Rideout JR, Dillon MR, et al (2019) Reproducible, interactive, scalable and extensible microbiome data science using QIIME 2. Nat Biotechnol 37:852-857. https://doi.org/10.1038/s41587-019-0209-9

9. Brinkmann N, Schneider D, Sahner J, et al (2019) Intensive tropical land use massively shifts soil fungal communities. Sci Rep 9:1-11. https://doi.org/10.1038/s41598-019-39829-4

10. Casamitjana M, Torres-Madroñero MC, Bernal-Riobo J, Varga D (2020) Soil moisture analysis by means of multispectral images according to land use and spatial resolution on Aandosols in the Colombian Andes. Appl Sci 10: https://doi.org/10.3390/app10165540

11. Castaño C, Dejene T, Mediavilla O, et al (2019) Changes in fungal diversity and composition along a chronosequence of Eucalyptus grandis plantations in Ethiopia. Fungal Ecol 39:328-335. https://doi.org/10.1016/j.funeco.2019.02.003

12. Cox F, Newsham KK, Robinson CH (2019) Endemic and cosmopolitan fungal taxa exhibit differential abundances in total and active communities of Antarctic soils. Environ Microbiol 21:1586-1596. https://doi.org/10.1111/1462-2920.14533

13. Essene AL, Shek KL, Lewis JD, et al (2017) Soil type has a stronger role than dipterocarp host species in shaping the ectomycorrhizal fungal community in a bornean lowland tropical rain forest. Front Plant Sci 8:1-10. https://doi.org/10.3389/fpls.2017.01828

14. Forin N, Nigris S, Voyron S, et al (2018) Next generation sequencing of ancient fungal specimens: The case of the saccardo mycological herbarium. Front Ecol Evol 6:1-19. https://doi.org/10.3389/fevo.2018.00129

15. Gao J, Liu M, Shi S, et al (2021) Disentangling responses of the subsurface microbiome to wetland status and implications for indicating ecosystem functions. Microorganisms 9:1-29. https://doi.org/10.3390/microorganisms 9020211

16. Gavito ME, Leyva-Morales R, Vega-Peña E V., et al (2019) Local-scale spatial diversity patterns of ectomycorrhizal fungal communities in a subtropical pine-oak forest. Fungal Ecol 42:. https://doi.org/10.1016/j.funeco.2019.08.004

17. Geml J, Pastor N, Fernandez L, et al (2014) Large-scale fungal diversity assessment in the Andean Yungas forests reveals strong community turnover among forest types along an altitudinal gradient. Mol Ecol 23:2452-2472. https://doi.org/10.1111/mec.12765

18. George PBL, Creer S, Griffiths RI, et al (2019) Primer and Database Choice Affect Fungal Functional but Not Biological Diversity Findings in a National Soil Survey. Front Environ Sci 7:173. https://doi.org/https://doi.org/10.3389/fenvs.2019.00173

19. Guerrero-Guerra C, Reyes-Montes MDR, Toriello C, et al (2013) Study of the persistence and viability of Metarhizium acridum in Mexico's agricultural area. Aerobiologia (Bologna) 29:249-261. https://doi.org/10.1007/s10453-012-9277-8

20. Hoyos-Carvajal L, Orduz S, Bissett J (2009) Genetic and metabolic biodiversity of Trichoderma from Colombia and adjacent neotropic regions. Fungal Genet Biol 46:615-631. https://doi.org/10.1016/j.fgb.2009.04.006

21. Ihrmark K, Bödeker ITM, Cruz-Martinez K, et al (2012) New primers to amplify the fungal ITS2 region - evaluation by 454sequencing of artificial and natural communities. FEMS Microbiol Ecol 82:666-677. https://doi.org/10.1111/j.15746941.2012.01437.x 
22. Jančič S, Zalar P, Kocev D, et al (2016) Halophily reloaded: new insights into the extremophilic life-style of Wallemia with the description of Wallemia hederae sp. nov. Fungal Divers 76:97-118. https://doi.org/10.1007/s13225-015-0333-x

23. Kassaye KT, Boulange J, Lam VT, et al (2020) Monitoring soil water content for decision supporting in agricultural water management based on critical threshold values adopted for Andosol in the temperate monsoon climate. Agric Water Manag 229:105930. https://doi.org/10.1016/j.agwat.2019.105930

24. Krüger M, Stockinger H, Krüger C, Schüßler A (2009) DNA-based species level detection of Glomeromycota: One PCR primer set for all arbuscular mycorrhizal fungi. New Phytol 183:212-223. https://doi.org/10.1111/j.1469-8137.2009.02835.x

25. Kumar S (2018) Molecular phylogeny and systematics of Glomeromycota: Methods and limitations. Plant Arch 18:1091-1101

26. Landinez-Torres A, Panelli S, Picco AM, et al (2019) A meta-barcoding analysis of soil mycobiota of the upper Andean Colombian agro-environment. Sci Rep 9:1-12. https://doi.org/10.1038/s41598-019-46485-1

27. Lauber CL, Ramirez KS, Aanderud Z, et al (2013) Temporal variability in soil microbial communities across land-use types. ISME J 7:1641-1650. https://doi.org/10.1038/ismej.2013.50

28. Li J, Delgado-Baquerizo M, Wang JT, et al (2019) Fungal richness contributes to multifunctionality in boreal forest soil. Soil Biol Biochem 136:107526. https://doi.org/10.1016/j.soilbio.2019.107526

29. Liu M, Liu J, Chen X, et al (2018) Shifts in bacterial and fungal diversity in a paddy soil faced with phosphorus surplus. Biol Fertil Soils 54:259-267. https://doi.org/10.1007/s00374-017-1258-1

30. Marín C, Godoy R, Valenzuela E, et al (2017) Functional land-use change effects on soil fungal communities in Chilean temperate rainforests. J Soil Sci Plant Nutr 17:985-1002. https://doi.org/10.4067/S0718-95162017000400011

31. Mašínová T, Bahnmann BD, Větrovský T, et al (2017) Drivers of yeast community composition in the litter and soil of a temperate forest. FEMS Microbiol Ecol 93:1-10. https://doi.org/10.1093/femsec/fiw223

32. McGuire A V., Northfield TD (2020) Tropical Occurrence and Agricultural Importance of Beauveria bassiana and Metarhizium anisopliae. Front Sustain Food Syst 4:. https://doi.org/10.3389/fsufs.2020.00006

33. McMurdie PJ, Holmes S (2013) Phyloseq: An R Package for Reproducible Interactive Analysis and Graphics of Microbiome Census Data. PLoS One 8:1-12. https://doi.org/10.1371/journal.pone.0061217

34. Mohammad Golam Dastogeer K, Oshita Y, Yasuda M, et al (2020) Host specificity of endophytic fungi from stem tissue of nature farming tomato (Solanum lycopersicum Mill.) in Japan. Agronomy 10:. https://doi.org/10.3390/agronomy10071019

35. Munguía-Pérez R, Díaz-Cabrera E, Martínez-Montiel N, et al (2011) Fungal diversity in soil samples from a Mexican region with endemic dermatomycoses. Micol Apl Int 23:11-19

36. Oksanen J, Guillaume Blanchet F, Friendly M, et al (2020) vegan: Community Ecology Package

37. Ontivero RE, Voyron S, Allione LVR, et al (2020) Impact of land use history on the arbuscular mycorrhizal fungal diversity in arid soils of Argentinean farming fields. FEMS Microbiol Lett 367:. https://doi.org/10.1093/femsle/fnaa114

38. Orgiazzi A, Bianciotto V, Bonfante P, et al (2013) 454 Pyrosequencing Analysis of Fungal Assemblages From Geographically Distant, Disparate Soils Reveals Spatial Patterning and a Core Mycobiome. Diversity 5:73-98. https://doi.org/10.3390/d5010073

39. Pang K-L, Guo S-Y, Chen I-A, et al (2019) Insights into fungal diversity of a shallow-water hydrothermal vent field at Kueishan Island, Taiwan by culture-based and metabarcoding analyses. PLoS One 14:e0226616. https://doi.org/10.1371/journal.pone.0226616

40. Pauvert C, Buée M, Laval V, et al (2019) Bioinformatics matters: The accuracy of plant and soil fungal community data is highly dependent on the metabarcoding pipeline. Fungal Ecol 41:23-33. https://doi.org/10.1016/j.funeco.2019.03.005

41. Pushkareva E, Baumann K, Van AT, et al (2021) Diversity of microbial phototrophs and heterotrophs in Icelandic biocrusts and their role in phosphorus-rich Andosols. Geoderma 386:114905. https://doi.org/10.1016/j.geoderma.2020.114905

42. Ritter CD, Dunthorn M, Anslan S, et al (2020) Advancing biodiversity assessments with environmental DNA: Long-read technologies help reveal the drivers of Amazonian fungal diversity. Ecol Evol 10:7509-7524. https://doi.org/10.1002/ece3.6477

43. Rosenfeld CE, James BR, Santelli CM (2018) Persistent Bacterial and Fungal Community Shifts Exhibited in SeleniumContaminated Reclaimed Mine Soils. Appl Environ Microbiol 84:612-625. https://doi.org/10.1128/aem.01394-18

44. Shi L, Dossa GGO, Paudel E, et al (2019) Changes in fungal communities across a forest disturbance gradient. bioRxiv 85:1-11. https://doi.org/10.1101/524132 
45. Simmons JA, Currie WS, Eshleman KN, et al (2008) Forest to reclaimed mine land use change leads to altered ecosystem structure and function. Ecol Appl 18:104-118. https://doi.org/10.1890/07-1117.1

46. Sommermann L, Geistlinger J, Wibberg D, et al (2018) Fungal community profiles in agricultural soils of a long-term field trial under different tillage, fertilization and crop rotation conditions analyzed by high-throughput ITS-amplicon sequencing. PLoS One 13.. https://doi.org/10.1371/journal.pone.0195345

47. Susha Lekshmi SU, Singh DN, Shojaei Baghini M (2014) A critical review of soil moisture measurement. Measurement 54:92105. https://doi.org/10.1016/j.measurement.2014.04.007

48. Suzuki K, Takahashi K, Harada N (2020) Evaluation of primer pairs for studying arbuscular mycorrhizal fungal community compositions using a MiSeq platform. Biol Fertil Soils 56:853-858. https://doi.org/10.1007/s00374-020-01431-6

49. Swan DM, Pustejovsky JE (2018) A Gradual Effects Model for Single-Case Designs. Multivariate Behav Res 53:574-593. https://doi.org/10.1080/00273171.2018.1466681

50. Tedersoo L, Bahram M, Põlme S, et al (2014) Global diversity and geography of soil fungi. Science (80- ) 346:1256688. https://doi.org/10.1126/science.1256688

51. Torondel B, Ensink JHJ, Gundogdu O, et al (2016) Assessment of the influence of intrinsic environmental and geographical factors on the bacterial ecology of pit latrines. Microb Biotechnol 9:209-223. https://doi.org/10.1111/1751-7915.12334

52. Turley NE, Bell-Dereske L, Evans SE, Brudvig LA (2020) Agricultural land-use history and restoration impact soil microbial biodiversity. J Appl Ecol 57:852-863. https://doi.org/https://doi.org/10.1111/1365-2664.13591

53. Urbina H, Scofield DG, Cafaro M, Rosling A (2016) DNA-metabarcoding uncovers the diversity of soil-inhabiting fungi in the tropical island of Puerto Rico. Mycoscience 57:217-227. https://doi.org/10.1016/j.myc.2016.02.001

54. Victorino ÍMM, Voyron S, Caser M, et al (2021) Metabarcoding of Soil Fungal Communities Associated with Alpine Field-Grown Saffron (Crocus sativus L.) Inoculated with AM Fungi. J Fungi 7:45. https://doi.org/10.3390/jof7010045

55. Wang JT, Zheng YM, Hu HW, et al (2015) Soil pH determines the alpha diversity but not beta diversity of soil fungal community along altitude in a typical Tibetan forest ecosystem. J Soils Sediments 15:1224-1232. https://doi.org/10.1007/s11368-0151070-1

56. White T, Bruns T, Lee S, et al (1990) Amplification and Direct Sequencing of Fungal Ribosomal RNA Genes for Phylogenetics. In: PCR Protocols: A guide to Methods and Amplifications. Academic Press, Inc., pp 315-322

57. Wu SY, El-Borai FE, Graham JH, Duncan LW (2019) Geospatial relationships between native entomopathogenic nematodes and Fusarium solani in a Florida citrus orchard. Appl Soil Ecol 140:108-114. https://doi.org/10.1016/j.apsoil.2019.04.009

58. Xiao E, Wang Y, Xiao T, et al (2021) Microbial community responses to land-use types and its ecological roles in mining area. Sci Total Environ 775:145753. https://doi.org/10.1016/j.scitotenv.2021.145753

59. Zhao X, Huang J, Lu J, Sun Y (2019) Study on the influence of soil microbial community on the long-term heavy metal pollution of different land use types and depth layers in mine. Ecotoxicol Environ Saf 170:218-226. https://doi.org/10.1016/j.ecoenv.2018.11.136

60. Zhou W hua, Wang Y tao, Lian Z han, et al (2020) Revegetation approach and plant identity unequally affect structure, ecological network and function of soil microbial community in a highly acidified mine tailings pond. Sci Total Environ 744:. https://doi.org/10.1016/j.scitotenv.2020.140793

\section{Tables}

Table.1 Data sequencing of ITS2 amplicons from Colombian Andosols. 


\begin{tabular}{|c|c|c|c|c|c|c|}
\hline $\begin{array}{l}\text { Land use/ } \\
\text { Specific } \\
\text { Activity }\end{array}$ & $\begin{array}{l}\text { Raw } \\
\text { sequences }\end{array}$ & $\begin{array}{l}\text { Total valid } \\
\text { sequences }\end{array}$ & $\begin{array}{l}\text { Average sequences } \\
\text { per sample }\end{array}$ & $\begin{array}{l}\text { Total OTUs } \\
\text { observed }\end{array}$ & $\begin{array}{l}\text { Min. number of } \\
\text { OTUs observed }\end{array}$ & $\begin{array}{l}\text { Max. number of } \\
\text { OTUs observed }\end{array}$ \\
\hline $\begin{array}{l}\text { Unperturbed } \\
\text { Areas }\end{array}$ & $1,414,082$ & 105,682 & 11,743 & 489 & 126 & 203 \\
\hline RN-pMWF ${ }^{1}$ & 497,376 & 30,478 & 10,160 & 167 & 53 & 57 \\
\hline ER- UnSH ${ }^{2}$ & 404,467 & 38,194 & 12,731 & 116 & 20 & 62 \\
\hline $\begin{array}{l}\text { LC- } \\
\text { MpMWF }^{3}\end{array}$ & 512,239 & 37,010 & 12,337 & 206 & 53 & 84 \\
\hline $\begin{array}{l}\text { Agricultural } \\
\text { Activities }\end{array}$ & $1,196,336$ & 112,374 & 12,486 & 297 & 84 & 118 \\
\hline $\mathrm{RN}-\mathrm{CF}^{4}$ & 334,723 & 25,434 & 8,478 & 120 & 39 & 41 \\
\hline ER- $\mathrm{CP}^{5}$ & 413,927 & 48,556 & 16,185 & 85 & 21 & 42 \\
\hline LC- $\mathrm{CH}^{6}$ & 447,686 & 38,384 & 12,795 & 92 & 24 & 35 \\
\hline $\begin{array}{l}\text { Mining } \\
\text { Extraction } \\
\text { Activities }\end{array}$ & 914,343 & 135,256 & 15,029 & 159 & 48 & 68 \\
\hline $\mathrm{RN}-\mathrm{CQC}^{7}$ & 393,152 & 45,908 & 15,303 & 83 & 16 & 31 \\
\hline ER- QC ${ }^{8}$ & 262,317 & 76,191 & 25,397 & 45 & 14 & 17 \\
\hline LC- $Q C^{9}$ & 258,874 & 13,157 & 4,386 & 31 & 15 & 16 \\
\hline
\end{tabular}

${ }^{1}$ Rionegro-Pre-montane wet forest; ${ }^{2}$ El Retiro-Unperturbed stubble height; ${ }^{3}$ La Ceja-Managed pre-montane wet forest; ${ }^{4}$ RionegroCrops of Fragaria ananassa; ${ }^{5}$ El Retiro-Forestry crops of Pinus sp.; ${ }^{6}$ La Ceja-Crops of Hydrangea sp.; ${ }^{7}$ Rionegro-Closed quarry clays; ${ }^{8}$ El Retiro-Quarry clays; ${ }^{9}$ La Ceja-Quarry clays.

Table.2 ITS2 sequences to Glomerycota families obtained by PCR heminested approach (primers mix SSUmCf Mix-ITS4 and fITS7ITS4) in samples retrieved from Colombian andosols. 


\begin{tabular}{|c|c|c|c|c|c|c|c|c|c|}
\hline \multirow[t]{2}{*}{ TAXA } & \multicolumn{3}{|c|}{ Unperturbed Areas } & \multicolumn{3}{|c|}{ Agricultural Areas } & \multicolumn{3}{|c|}{ Mining Extraction Areas } \\
\hline & $\begin{array}{l}\text { RN- } \\
\text { pMWF }^{1}\end{array}$ & $\begin{array}{l}\text { ER- } \\
\text { UpSH }^{2}\end{array}$ & $\begin{array}{l}\text { LC- } \\
\text { MpMWF }^{3}\end{array}$ & $\begin{array}{l}\mathrm{RN}- \\
\mathrm{CF}^{4}\end{array}$ & $\begin{array}{l}\text { ER- } \\
\mathrm{CP}^{5}\end{array}$ & $\begin{array}{l}\text { LC- } \\
\mathrm{CH}^{6}\end{array}$ & $\begin{array}{l}\mathrm{RN}- \\
\mathrm{CQC}^{7}\end{array}$ & $\begin{array}{l}\text { ER- } \\
\text { QC }^{8}\end{array}$ & $\begin{array}{l}\text { LC- } \\
\mathrm{QC}^{9}\end{array}$ \\
\hline Order Archaeosporales & 74 & 4707 & 237 & 568 & 1436 & 402 & 60 & 953 & 1470 \\
\hline F_Ambisporaceae & 0 & 0 & 0 & 0 & 0 & 0 & 0 & 0 & 75 \\
\hline F_Archaeosporaceae & 0 & 86 & 51 & 497 & 108 & 353 & 0 & 0 & 847 \\
\hline F_Unidentified & 74 & 4621 & 186 & 71 & 1328 & 49 & 60 & 953 & 548 \\
\hline Order Diversisporales & 0 & 0 & 0 & 0 & 0 & 0 & 0 & 0 & 16 \\
\hline F_Acaulosporaceae & 0 & 0 & 0 & 0 & 0 & 0 & 0 & 0 & 16 \\
\hline Order Glomerales & 149 & 0 & 88 & 30 & 0 & 40 & 107 & 0 & 103 \\
\hline F_Claroideoglomeraceae & 149 & 0 & 88 & 0 & 0 & 40 & 107 & 0 & 103 \\
\hline F_Glomeraceae & 0 & 0 & 0 & 30 & 0 & 0 & 0 & 0 & 0 \\
\hline Order unidentified & 0 & 47 & 0 & 0 & 0 & 42 & 0 & 0 & 0 \\
\hline
\end{tabular}

${ }^{1}$ Rionegro-Pre-montane wet forest; ${ }^{2}$ El Retiro-Unperturbed stubble height; ${ }^{3}$ La Ceja-Managed pre-montane wet forest; ${ }^{4}$ RionegroCrops of Fragaria ananassa; ${ }^{5}$ El Retiro-Forestry crops of Pinus sp.; ${ }^{6}$ La Ceja-Crops of Hydrangea sp.; ${ }^{7}$ Rionegro-Closed quarry clays; ${ }^{8}$ El Retiro-Quarry clays; ${ }^{9}$ La Ceja-Quarry clays.

Table.3 Prevalent fungal species in Colombian Andosols retrieved from Unperturbed Areas (UnPA), Agricultural Areas (AgA) and Mining Extraction Areas (MeA). 


\begin{tabular}{|c|c|c|c|}
\hline Land use & Specie & Average prevalence & Total reads \\
\hline \multirow[t]{6}{*}{ UnPA } & Saitozyma sp. & 5 & 239 \\
\hline & Metarhizium anisopliae & 4.5 & 1157 \\
\hline & Fusarium solani & 4 & 48 \\
\hline & Trichoderma asperellum & 4 & 528 \\
\hline & Apiotrichum scarabaeorum & 3 & 604 \\
\hline & Clonostachys sp. & 3 & 105 \\
\hline \multirow[t]{6}{*}{ AgA } & Trichoderma asperellum & 5 & 432 \\
\hline & Agrocybe pediades & 3 & 16 \\
\hline & Pholiota abieticola & 3 & 38 \\
\hline & Pochonia sp. & 3 & 112 \\
\hline & Suillus cothurnatus & 3 & 25 \\
\hline & Malassezia sp. & 2.5 & 647 \\
\hline \multirow[t]{6}{*}{$\mathrm{MeA}$} & Agrocybe pediades & 3 & 129 \\
\hline & Rhizopogon verii & 2.5 & 34 \\
\hline & Clathrus archeri & 2 & 9 \\
\hline & Coprinus sp. & 2 & 19 \\
\hline & Hygrocybe sp. & 2 & 28 \\
\hline & Malassezia sp. & 2 & 2546 \\
\hline
\end{tabular}

Table.4 Average of environmental and physico-chemical parameters in Colombian Andosols under different land uses from Colombian Andosols retrieved in Rionegro (RN), El Retiro (ER) and La Ceja (LC). 


\begin{tabular}{|c|c|c|c|c|c|c|c|c|c|}
\hline $\begin{array}{l}\text { Land use/ } \\
\text { Specific } \\
\text { Activity }\end{array}$ & $\begin{array}{l}\text { Soil } \\
\text { temperature } \\
\left({ }^{\circ} \mathrm{C}\right)\end{array}$ & $\begin{array}{l}\text { Dew point } \\
\text { temperature } \\
\left({ }^{\circ} \mathrm{C}\right)\end{array}$ & $\begin{array}{l}\text { Relative } \\
\text { air } \\
\text { humidity } \\
(\%)\end{array}$ & $\begin{array}{l}\text { Barometric } \\
\text { pressure } \\
(\mathrm{hPa})\end{array}$ & $\mathrm{pH}$ & $\begin{array}{l}\text { Electrical } \\
\text { conductivity } \\
\text { (ds/ms) }\end{array}$ & $\begin{array}{l}\text { Total } \\
\text { dissolved } \\
\text { solids } \\
(\mathrm{ppm})\end{array}$ & $\begin{array}{l}\text { Moisture } \\
\text { (\%) }\end{array}$ & $\begin{array}{l}\text { Organic } \\
\text { matter } \\
(\%)\end{array}$ \\
\hline $\begin{array}{l}\text { Unperturbed } \\
\text { Areas }(\mathrm{N}=9)\end{array}$ & 18.28 & 14.87 & 80.71 & 763.80 & 5.43 & 667.78 & 332.15 & 21.28 & 10.56 \\
\hline $\begin{array}{l}\mathrm{RN}-\text { Pre- } \\
\text { montane } \\
\text { wet forest ( } \\
=3 \text { ) }\end{array}$ & 18.24 & 15.20 & 82.73 & 743.41 & 5.37 & 781.33 & 407.78 & 23.20 & 10.75 \\
\hline $\begin{array}{l}\text { ER- } \\
\text { Unperturbed } \\
\text { stubble } \\
\text { height ( } \\
=3 \text { ) }\end{array}$ & 18.96 & 14.96 & 77.81 & 769.42 & 5.73 & 818.67 & 405.56 & 22.48 & 9.73 \\
\hline $\begin{array}{l}\text { LC- } \\
\text { Managed } \\
\text { pre-montane } \\
\text { wet forest (N } \\
=3 \text { ) }\end{array}$ & 17.64 & 14.45 & 81.60 & 778.56 & 5.18 & 403.33 & 183.11 & 18.16 & 11.21 \\
\hline $\begin{array}{l}\text { Agricultural } \\
\text { Activities (N } \\
=9 \text { ) }\end{array}$ & 18.08 & 14.38 & 79.41 & 766.04 & 5.36 & 680.67 & 363.00 & 21.55 & 8.55 \\
\hline $\begin{array}{l}\text { RN-Crops of } \\
\text { Fragaria } \\
\text { ananassa ( } \\
=3 \text { ) }\end{array}$ & 17.03 & 13.49 & 79.99 & 755.80 & 5.07 & 769.00 & 396.33 & 23.87 & 9.11 \\
\hline $\begin{array}{l}\text { ER- Forestry } \\
\text { crops of } \\
\text { Pinus } s p \text {. (N } \\
=3 \text { ) }\end{array}$ & 17.99 & 14.23 & 79.36 & 774.11 & 5.73 & 898.00 & 453.78 & 24.28 & 9.11 \\
\hline $\begin{array}{l}\text { LC- Crops of } \\
\text { Hydrangea } \\
\text { sp. }(\mathrm{N}=3)\end{array}$ & 19.21 & 15.44 & 78.89 & 768.22 & 5.29 & 375.00 & 238.89 & 16.51 & 7.42 \\
\hline $\begin{array}{l}\text { Mining } \\
\text { Extraction } \\
\text { Activities ( } \mathrm{N} \\
=9 \text { ) }\end{array}$ & 22.15 & 15.60 & 67.40 & 753.76 & 5.53 & 853.75 & 420.17 & 12.54 & 4.10 \\
\hline $\begin{array}{l}\mathrm{RN}-\text { Closed } \\
\text { quarry clays } \\
(\mathrm{N}=3)\end{array}$ & 20.92 & 13.94 & 64.48 & 736.09 & 5.54 & 845.00 & 404.45 & 7.68 & 2.92 \\
\hline $\begin{array}{l}\text { ER- Quarry } \\
\text { clays }(\mathrm{N}=3)\end{array}$ & 24.48 & 16.37 & 61.46 & 765.91 & 5.47 & 876.33 & 448.89 & 15.61 & 5.80 \\
\hline $\begin{array}{l}\text { LC- Quarry } \\
\text { clays }(N=3)\end{array}$ & 20.51 & 16.92 & 80.70 & 762.06 & 5.61 & 833.00 & 400.67 & 15.21 & 3.33 \\
\hline
\end{tabular}

Number of samples averaged $(\mathrm{N})$.

Table.5 Absolute Response Ratio Average to fungal features, physicochemical and environmental parameters observed to comparisons between Colombian Andosols retrieved from Unperturbed Areas (UnPA) and Agricultural activities (AgA) or Mining extraction activities (MeA). 


\begin{tabular}{|lll|}
\hline & \multicolumn{2}{l|}{ CONTRASTING } \\
\hline INDICATOR & UnPA vs. AgA & UnPA vs. MeA \\
\hline Abundances prevalent species* & 2.24 & 4.167 \\
\hline Abundances dominant order* & 1.837 & 3.002 \\
\hline Alpha diversity index values* & 0.462 & 0.999 \\
\hline Soil properties & 0.025 & 0.172 \\
\hline Environmental parameter* & 0.005 & 0.03 \\
\hline
\end{tabular}

* Differences significant at $p$-value $<0.05$ to Wilcoxon rank sum test with continuity correction.

\section{Figures}
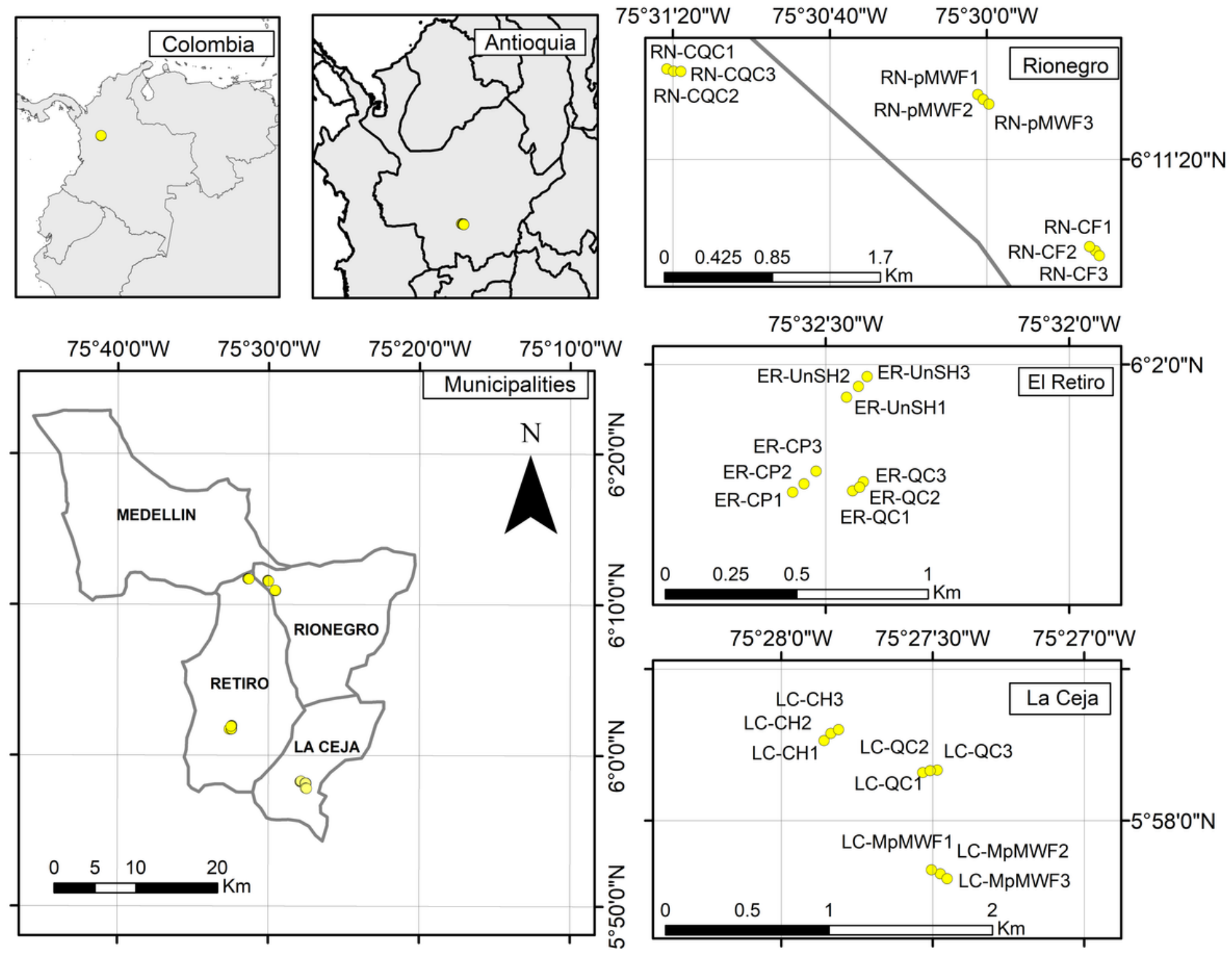

Figure 1

Geolocation of 27 soil samples retrieved from Colombian Andosols in Rionegro Closed quarry clays (RN-CQC1, 2, 3), Crops of Fragaria ananassa (RN-CF1, 2, 3) and Pre-montane wet forest (RN-pMWF1, 2, 3); El Retiro Quarry clays (ER-QC1, 3), Forestry crops of Pinus sp. 
(ER-CP1, 2, 3) and Unperturbed stubble height (ER-UnSH1, 2, 3); La Ceja Quarry clays (LC-QC1, 2, 3), Crops of Hydrangea sp. (LC-CH1, 2, 3) and Managed pre-montane wet forest (LC-MpMWF1, 2, 3).

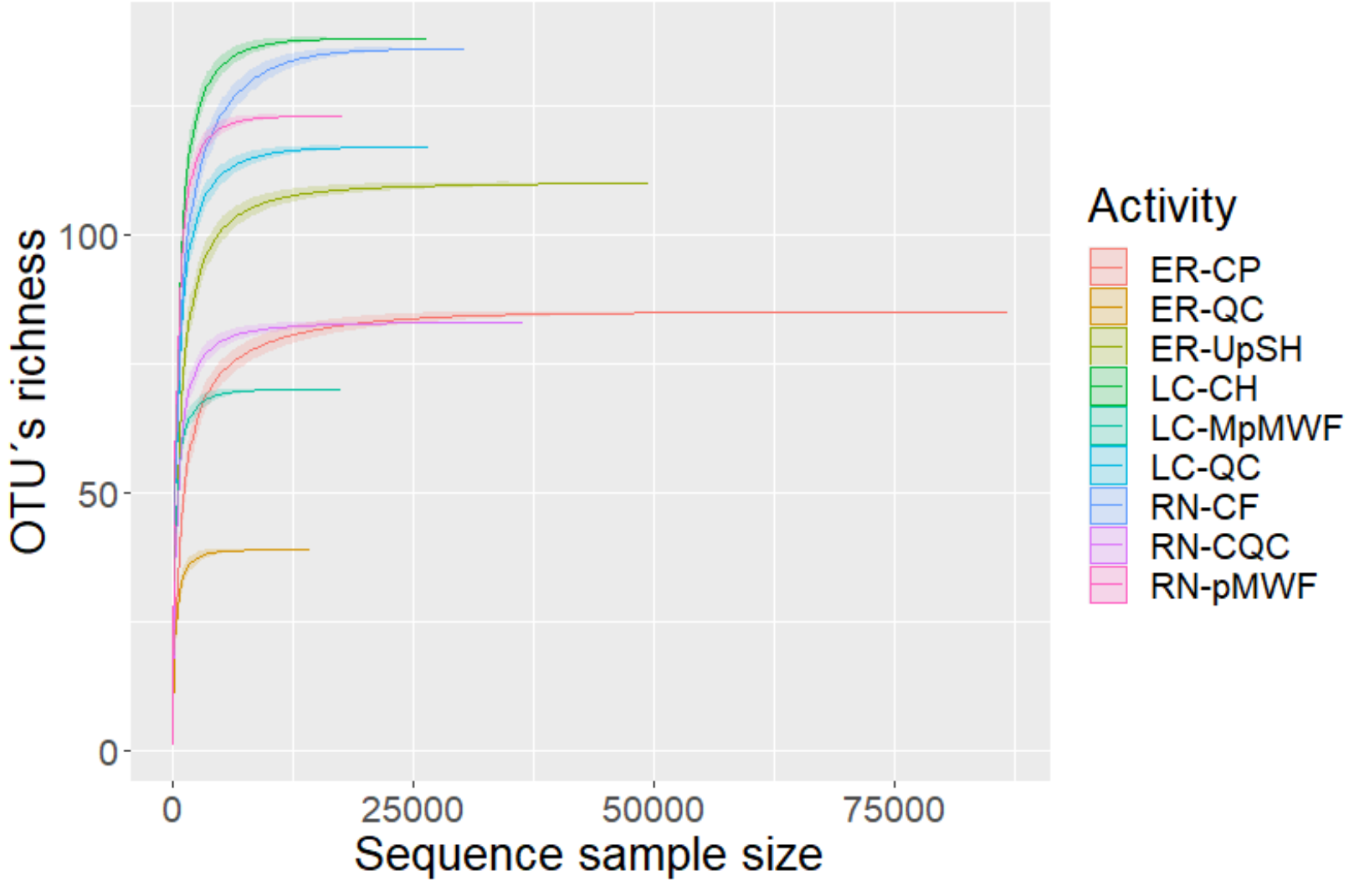

Figure 2

Rarefaction curves showing observed OTUs richness in samples taken from "Rionegro": Closed quarry clays (RN-CQC), Crops of Fragaria ananassa (RN-CF) and Pre-montane wet forest (RN-pMWF); “El Retiro”: Quarry clays (ER-QC), Forestry crops of Pinus sp. (ER$\mathrm{CP}$ ) and Unperturbed stubble height (ER-UnSH); "La Ceja”: Quarry clays (LC-QC), Crops of Hydrangea sp. (LC-CH) and Managed premontane wet forest (LC-MpMWF). 


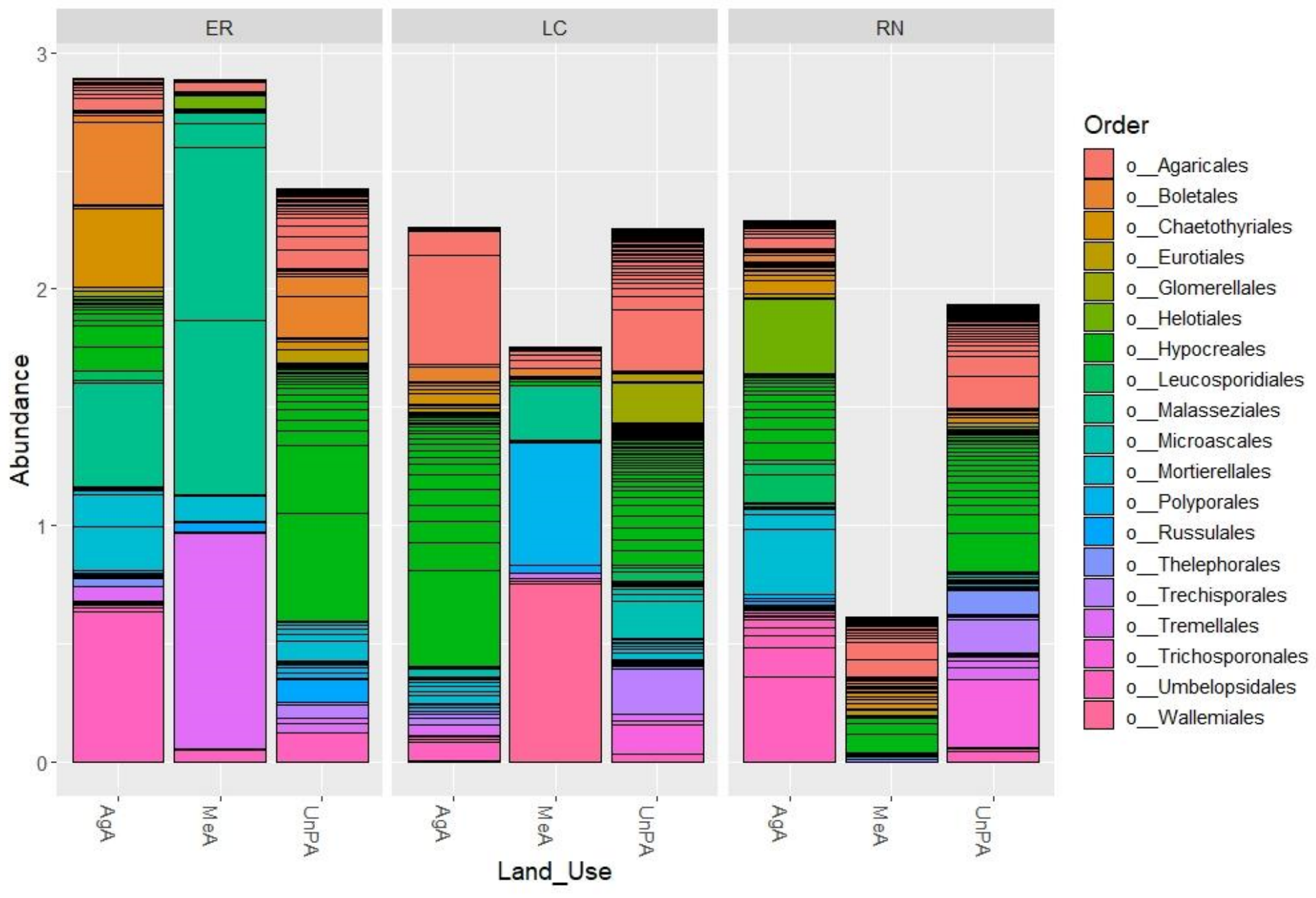

Figure 3

Abundances of fungal dominant order in municipalities of Rionegro (RN), El Retiro (ER) and La Ceja (LC). Soil sampled in areas of Agricultural activities (AgA), Mining extraction activities (MeA) and Unperturbed areas (UnPA). 

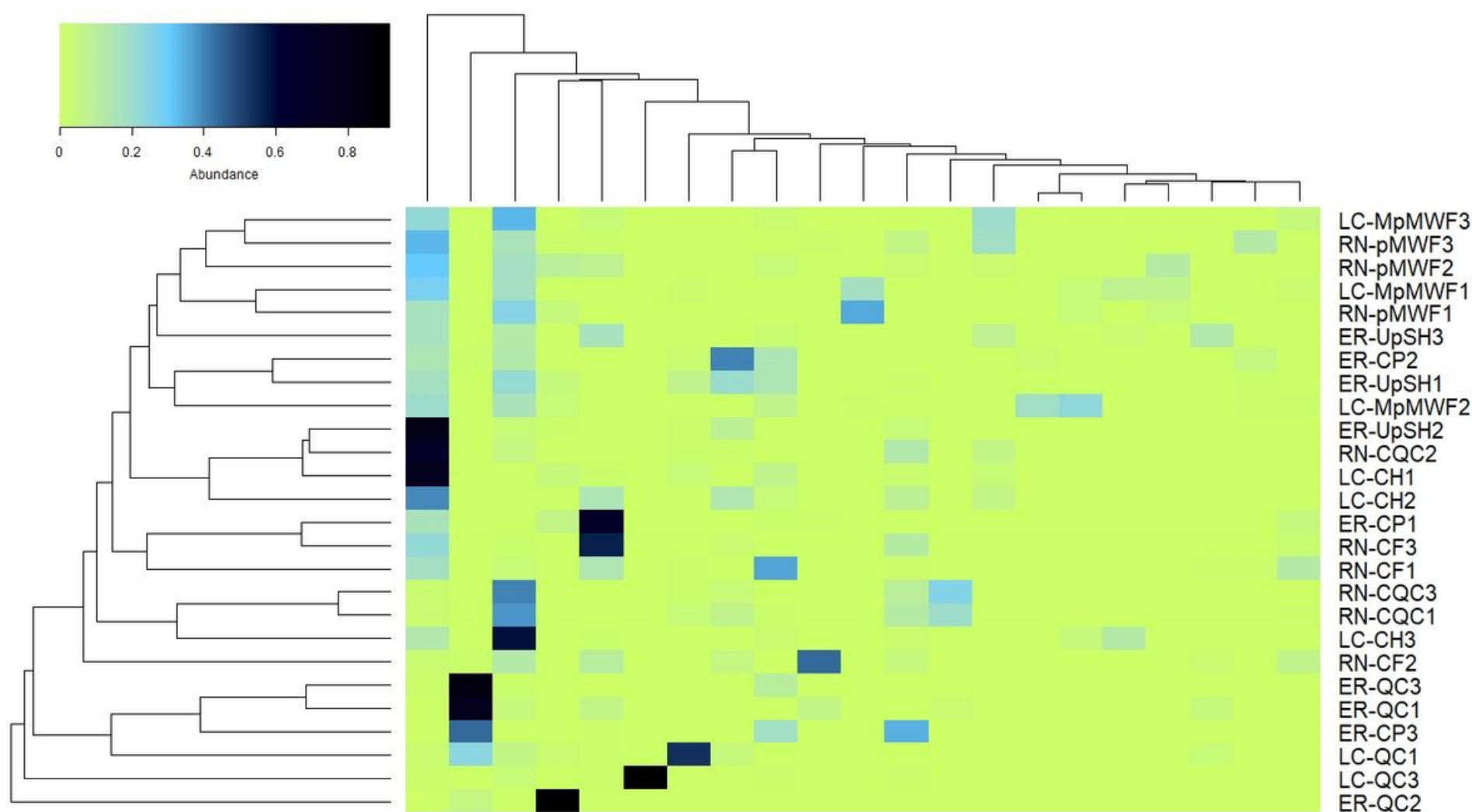

RN-pMWF3

LC-MpMWF1

RN-pMWF1

ER-UpSH3

ER-CP2

ER-UpSH1

LC-MpMWF2

ER-UpSH2

$\mathrm{RN}-\mathrm{CQC2}$

LC-CH1

LC-CH2

ER-CP1

$\mathrm{RN}-\mathrm{CF} 3$

RN-CF1

$\mathrm{RN}-\mathrm{CQC3}$

$\mathrm{RN}-\mathrm{CQC1}$

$\mathrm{LC}-\mathrm{CH} 3$

RN-CF2

ER-QC3

ER-QC1

ER-CP3

LC-QC1

LC-QC3

ER-QC2

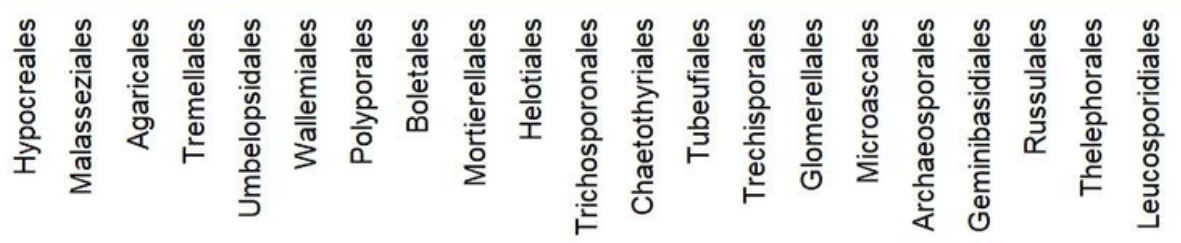

\section{Figure 4}

Heatmap and hierarchical cluster analysis based on Bray-Curtis transformed abundance data for OTUs of fungal dominant order in 26 soil samples from "Rionegro": Closed quarry clays (RN-CQC1, 2, 3), Crops of Fragaria ananassa (RN-CF1, 2, 3) and Pre-montane wet forest (RN-pMWF1, 2, 3); "El Retiro": Quarry clays (ER-QC1, 3), Forestry crops of Pinus sp. (ER-CP1, 2, 3) and Unperturbed stubble height (ER-UnSH1, 2, 3); "La Ceja": Quarry clays (LC-QC1, 2, 3), Crops of Hydrangea sp. (LC-CH1, 2, 3) and Managed pre-montane wet forest (LC-MpMWF1, 2, 3). 

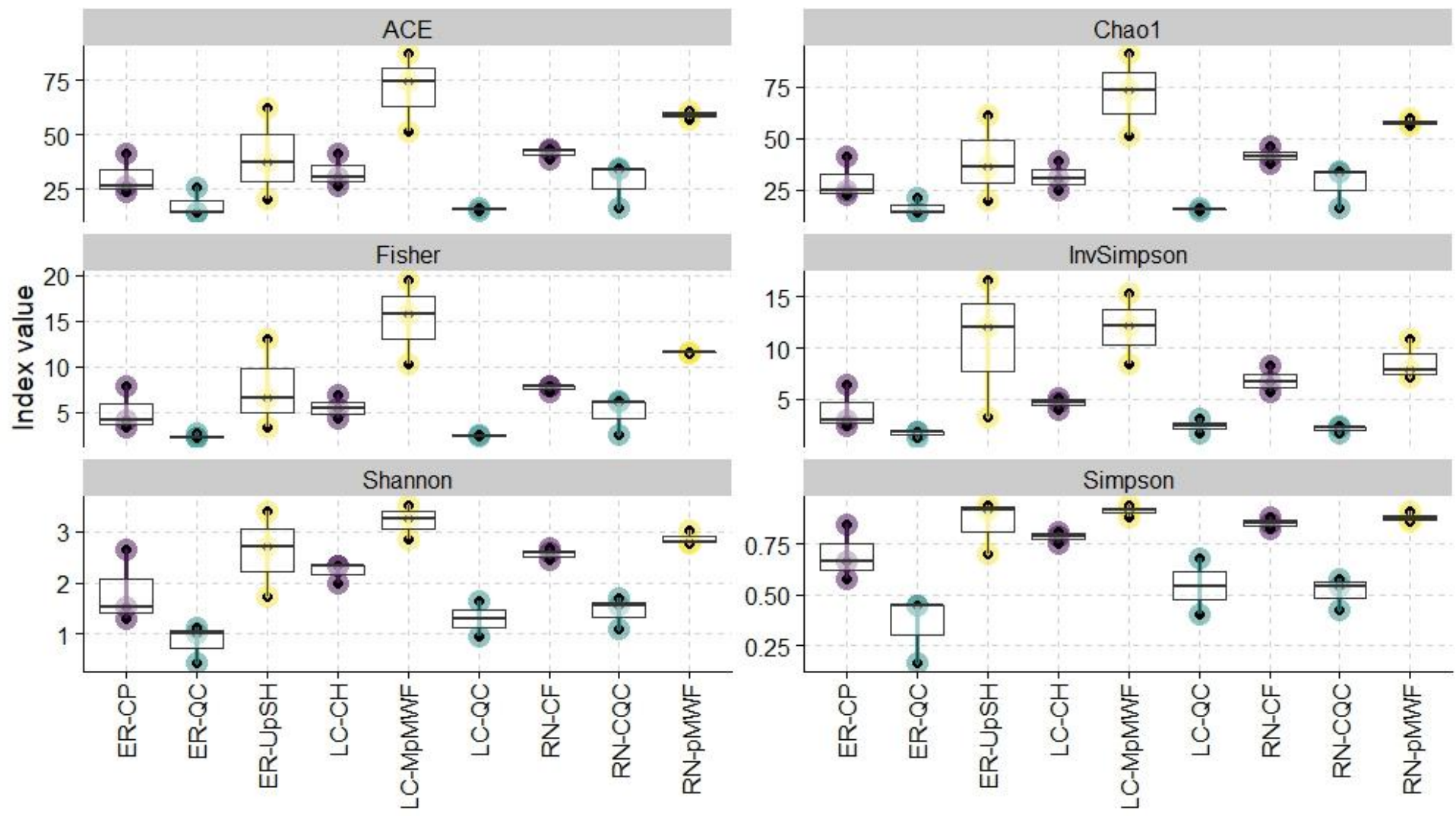

Activity

Land_use $=\mathrm{AgA}=\mathrm{MeA}=\mathrm{UnPA}$

\section{Figure 5}

Alpha diversity indexes to fungal communities of Colombian Andosols retrieved in "El Retiro": Forestry crops of Pinus sp. (ER-CP), Quarry clays (ER-QC) and Quarry clays (ER-QC); "La Ceja”: Crops of Hydrangea sp. (LC-CH), Managed pre-montane wet forest (LCMpMWF) and Quarry clays (LC-QC); "Rionegro”: Crops of Fragaria ananassa (RN-CF), Closed quarry clays (RN-CQC) and Pre-montane wet forest (RN-pMWF). The indexes were calculated from OTUs relative abundance of each replicate. 

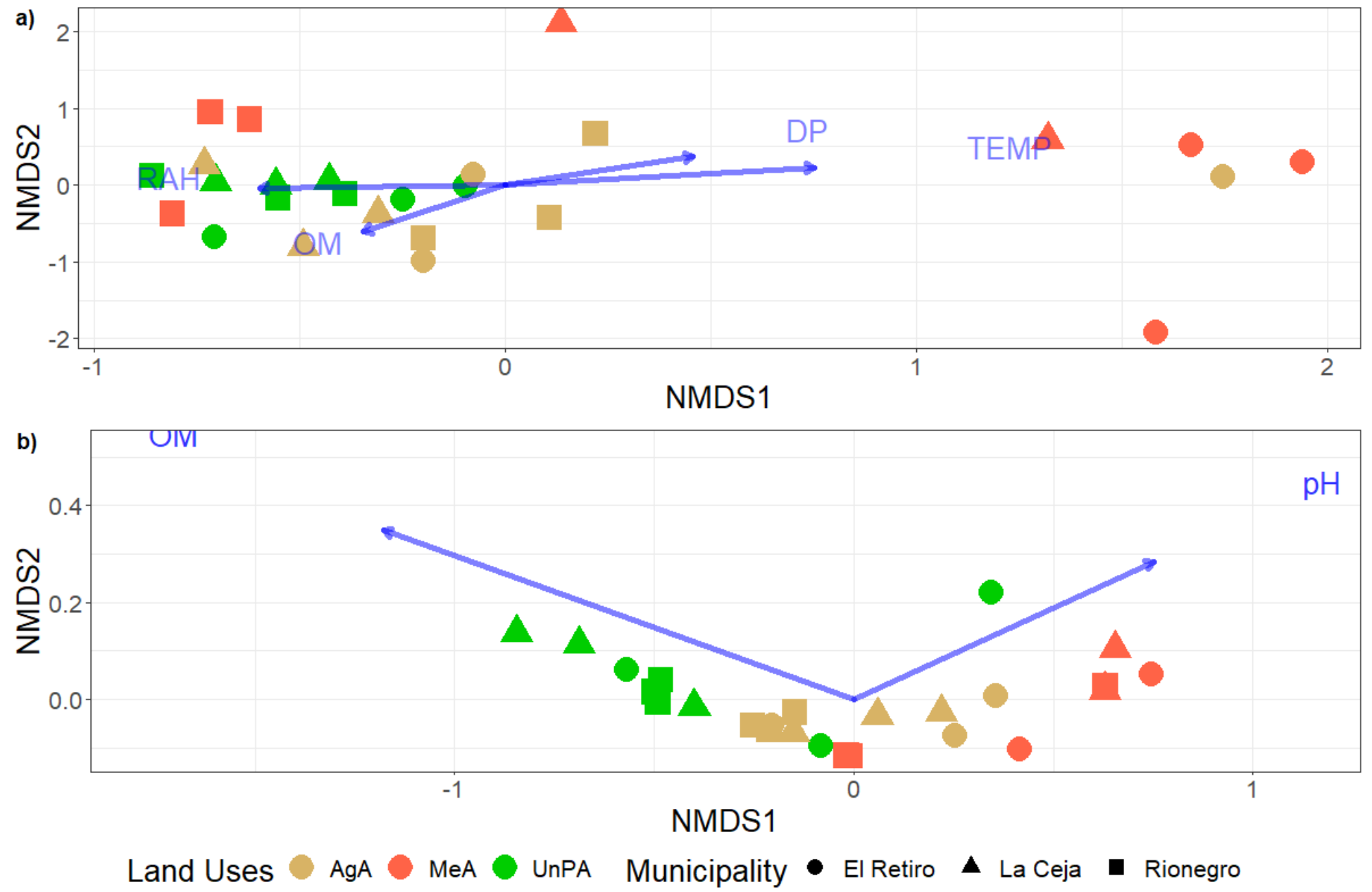

Figure 6

Non-metric multidimensional scaling of 26 soil samples in Colombian Andosols with driver factors. a) Ordination based on order compositions (Stress value $=0.1457$ ) and $b$ ) Ordination based on alpha diversity index values (Stress value $=0.008)$. (AgA=Agricultural activities, MeA=Mining extraction activities, UnPA=Unperturbed areas, $\mathrm{DP}=$ dew point temperature, $\mathrm{OM}=$ organic matter, $\mathrm{RAH}=\mathrm{relative}$ air humidity, TEMP=Soil temperature). 
a)

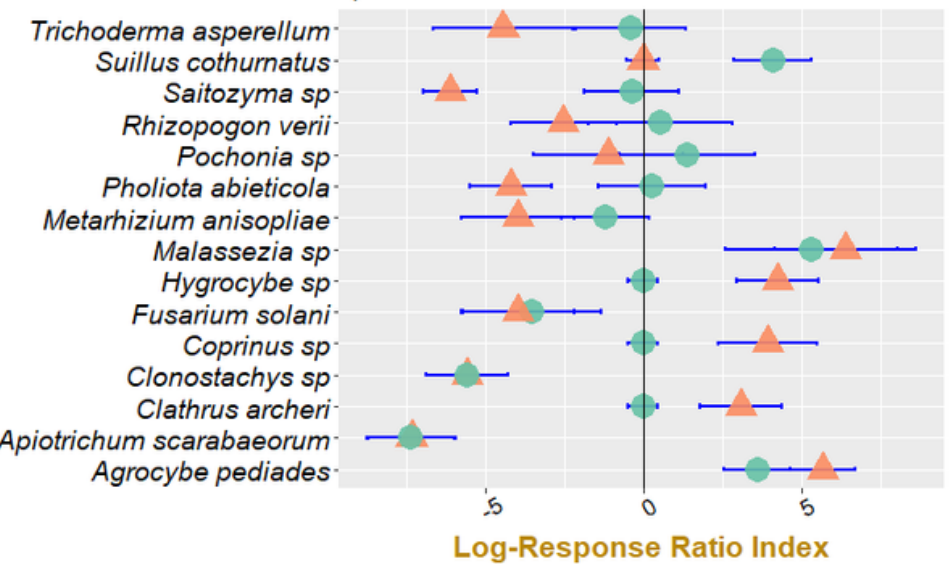

c)

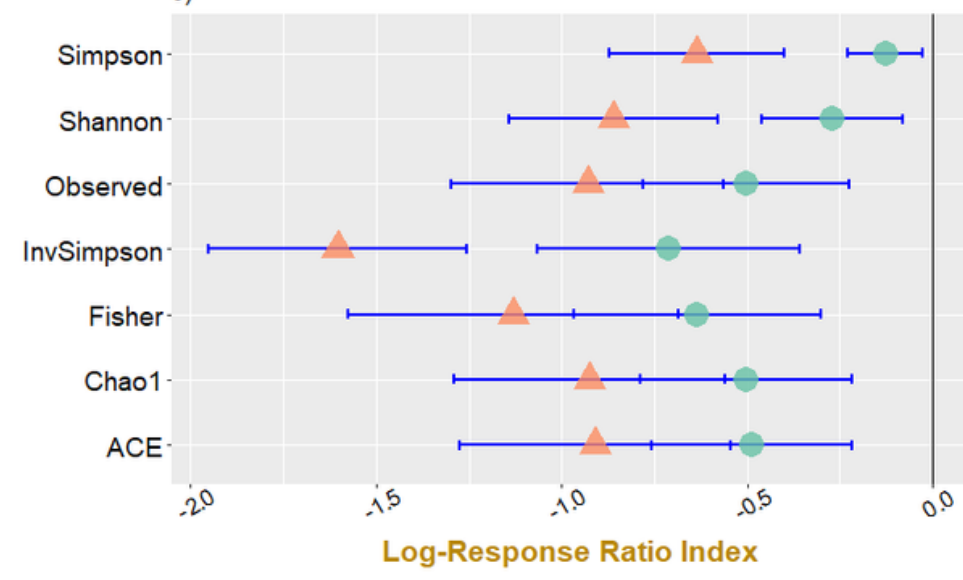

b)

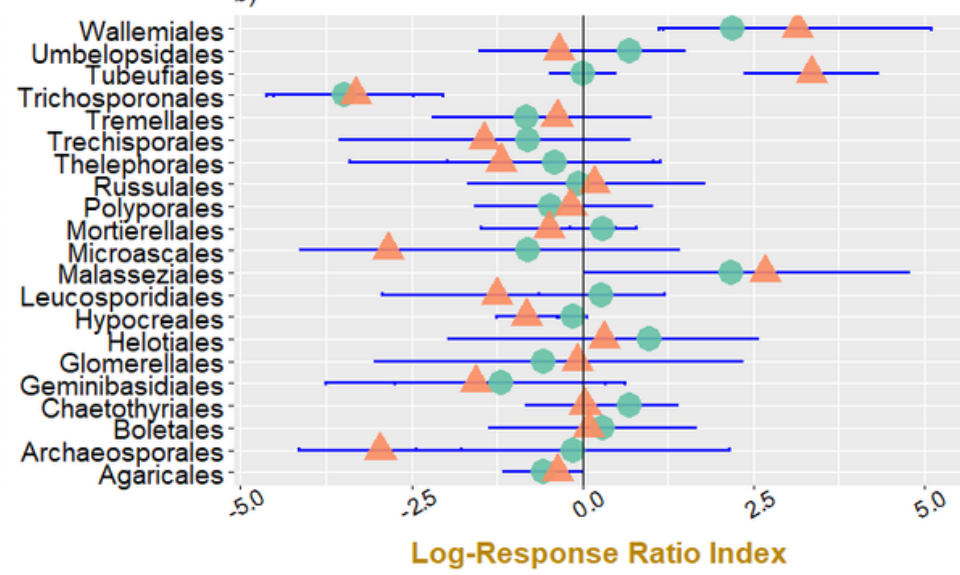

d)

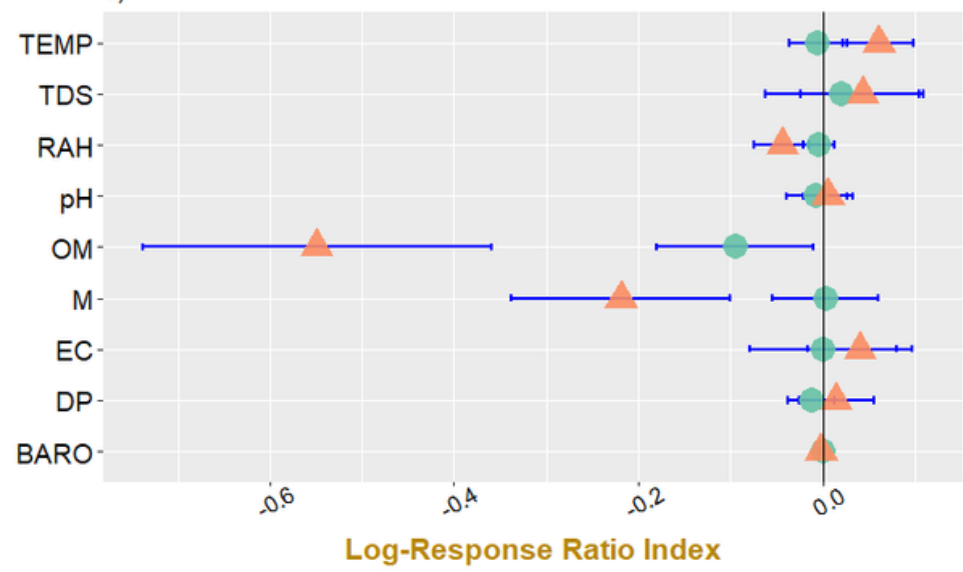

Land use comparison

UnPA vs. AgA $\boldsymbol{\Delta}$ UnPA vs. MeA

\section{Figure 7}

Response Ratio Indexes of a) Abundances of prevalent species; b) Abundances of dominant order; c) Alpha diversity values; d) Soil properties and environmental parameter. The RRi was considered significant when the $95 \%$ confidence interval (presented as error bars) does not overlap with 0 . (TEMP=Soil temperature, $\mathrm{DP}=\mathrm{Dew}$ point temperature, $\mathrm{RAH}=\mathrm{Relative}$ air humidity, $\mathrm{BARO}=\mathrm{Barometric}$ pressure, EC=Electrical conductivity, TDS=Total dissolved solids, $\mathrm{M}=$ Soil moisture, $\mathrm{OM}=$ Organic Matter, AgA=Agricultural activities, MeA=Mining extraction activities, UnPA=Unperturbed 